\title{
Editorial
}

\section{Defining Suicidology and the Titling of Suicidologist?}

\author{
Alan L. Berman' ${ }^{1}$ Morton M. Silverman², \\ Diego De Leo ${ }^{3,4}$, and Daniel Reidenberg ${ }^{5}$
}

1'Department of Psychiatry and Behavioral Sciences, Johns Hopkins University School of Medicine, Baltimore, MD, USA

2Department of Psychiatry, Medical College of Wisconsin, Milwaukee, WI, USA
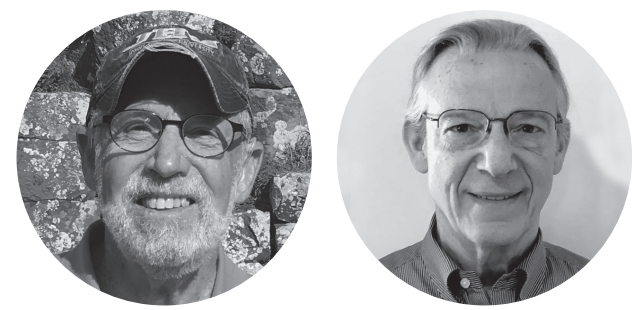

${ }^{3}$ Australian Institute for Suicide Research and Prevention, Griffith University, Mount Gravatt, QLD, Australia

"Slovene Centre for Suicide Research, University of Primorska, Slovenia

${ }^{5}$ Suicide Awareness Voices of Education, Minneapolis, MN, USA

In January 1970, the US National Institute of Mental Health (NIMH) held a historic conference on suicide and suicide prevention in Phoenix, Arizona. Fifty leaders and students in the field of suicide prevention convened for 3 days to "consider the state of suicide prevention in general with particular attention to establishing directions and priorities for the field" for the next decade (Hathorne \& Resnik, 1973, p. v). Six working committees were created and tasked with formulating a set of recommendations to be considered for the conference's final report. Notably, the Committee on Education and Training's primary objective was to give shape and form to the aborning profession of suicidology by addressing the question of how to educate and train one who is to be a suicidologist.

Suicidology appropriately was described as an "aborning profession" because the field had only been given its name, its social identity, a few years earlier. The study of suicide and its prevention has a long history dating back, at the least, to the late 1700s (Goldney, Schioldann, \& Dunn, 2008). But, similar to cultures in which infant mortality is sufficiently high that the naming of newborns may be delayed until it is deemed likely that they will survive (McCormick, 2010), the term suicidology was not officially used until 1967 when Edwin Shneidman gave birth to a new journal, the Bulletin of Suicidology (Shneidman, 1989, p. 255). In the foreword to that journal's first issue (Shneidman \& Swenson, 1967), Stanley Yolles, the then-director of the NIMH, wrote:

Initiation of the BULLETIN signals the inauguration of a new profession, Suicidology, the study of suicidal phenomena and their prevention. We conceive of Suicidology as a uniquely interdisciplinary profession, involving individuals with a wide variety of backgrounds in science, medicine, health, and allied fields. (p. 1)
An "ology" references a discipline or field of study and generally implies a scientific study of its subject matter. But not all "ologies" are scientific in nature. As noted above, suicidology was founded within the walls of the United States premier research organization (the NIMH), by mental health professionals with a shared mission to scientifically study "suicidal phenomena and their prevention."

\section{Is Suicidology a Profession, a Specialization, or a Vocation?}

The Merriam and Webster's Dictionary defines a profession as "a calling requiring specialized knowledge and often an intensive academic preparation" (https://www.merriamwebster.com/dictionary/profession). Paraphrasing an Australian definition, a profession is a discipline comprising individuals who adhere to ethical standards, possess special knowledge and skills in a recognized body of learning derived from research, education, and training at a high level, and is recognized by the public as such. One who practices that profession, a professional, is defined as "one conforming to the technical or ethical standards of a profession" (https://www.merriam-webster.com/dictionary/professional). Professionals are prepared to apply their knowledge and exercise their skills in the interest of others (https:// www.psc.gov.au/what-is-a-profession).

Denoting suicidology as a profession, therefore, assumes that the field has defined its core specialized knowledge that suicidologists (the profession's practitioners) achieve through intensive academic preparation and that the field has a set of ethical standards adhered to by suicid- 
ologists. None of these defining criteria appear to be well met currently by the field of suicidology.

As suicidology may well be described as transdisciplinary, that is, an area of interest concentrated on by a variety of professions/professionals, it, itself, does not qualify as a unique profession. Moreover, although suicidology is an area of interest to a variety of trained individuals, very few of these individuals have either been trained in suicidology (see below) or bring their own multidisciplinary perspective to this area of interest (e.g., few researchers are concurrently skilled clinical providers, few sociologists at once are skilled in epidemiology, etc.).

Among those individuals with training, certification, and/or license to practice their chosen profession who, then, concentrate their interest and efforts in suicidology, suicidology might be better construed as a specialization, akin to the way obstetrics or neurosurgery are subareas of medicine requiring specialized learnings and training. Specializations were essential for the progress of medicine, emerging in the early 19th century "as a form of knowledge production and diffusion, ...closely linked to clinical practice" to characterize "a community of scholars built around a research imperative" (Weisz, 2003, pp. 539-540, 574). Indeed, when we examine the roots of suicidology, as envisioned and initiated by Shneidman, it was conceived as a community of interdisciplinary scholars, defined by a journal devoted to its object of study (Bulletin of Suicidology) with a research imperative to inform clinical intervention and prevention. A community of scholars was envisioned and created by Shneidman when he convened a meeting in Chicago in 1968 at which he hosted a group comprising a philosopher (Jacque Choron), a statistician (Louis Dublin), a psychoanalyst (Paul Friedman), an educator (Robert Havighurst), and three psychiatrists (Lawrence Kubie, Karl Menninger, and Erwin Stengel). That meeting immediately preceded the founding of the American Association of Suicidology (Shneidman, 1989). Similarly, the International Association for Suicide Prevention was founded in Vienna, in 1960, by an Austrian psychiatrist (Erwin Ringel) and an American psychologist (Norman Farberow).

Although the foundation of suicidology rests on the scientific study of suicide, suicidal individuals, and the prevention of suicide, many who have become involved in these endeavors are neither scientists nor, themselves, professionals. Crisis center volunteers, paraprofessionals, those with lived experience, and loss survivors, among other nonprofessionals, have added immeasurably to the global growth of and interest in suicide prevention and postvention. For these individuals suicidology may better be construed as a vocation, restricting the meaning of vocation to that of its Latin derivation as that of a "calling." This appellation is fitting for many who might call them- selves suicidologists given the definition of vocation as that which gives purpose to one's life, such as volunteering for a charity. In this sense, a suicidologist is one who transmits, shares, or uses their understanding of suicidal phenomena for the common good, irrespective of whether or not one holds an advanced degree, certification, and/or license as a professional.

Accepting that suicidology is a specialization for those who have had specialized academic preparation and research credentials, and a vocation for others, questions remain as to whether those who choose to call themselves suicidologists should be expected to meet certain criteria relative to attaining a degree of knowledge and competency in the subject matter of suicidology, no less to abide by a shared code of ethics, specific to the field of suicidology. These questions pertain more, but not solely, to professionals. As described a half century ago by the Phoenix Conference's Committee on Education and Training, "Put succinctly, the nub of the problem is how can we make one (viz., a Suicidologist), if we do not know what one is or does?” (p. 23).

\section{Suicidology as an Interest Area}

In medicine, specialties such as cardiology, internal medicine, or psychiatry have established and defined both training requirements and knowledge competencies that must be achieved before one with a medical degree can be licensed or board certified in their chosen specialty. Furthermore, specialties such as psychiatry have subspecialties, such as child and adolescent psychiatry, which require additional training, credentialing, etc. Similarly, psychology has a great number of subdisciplines, such as clinical, experimental, developmental, social, and organizational, each requiring specialized training and demonstration of knowledge competencies. In other disciplines, perhaps more akin to suicidology, such as criminology, an advanced degree and specific academic training is generally expected of one who would be a criminologist. For the time being, neither an advanced degree nor specific training is required of those who may choose to call themselves suicidologists. Within both medicine and psychology there are topic areas of specialized interest. In medicine, a physician can have an interest in global health or sleep, for example. In psychology, a psychologist can join with like-minded colleagues to study social issues or esthetics and creativity. It would seem that for most suicidologists, the field of suicidology might best be described as an area of (research, clinical, prevention science, personal, etc.) interest, rather than a profession, specialty, or subspecialty. 
Left unaddressed and unanswered, however, is the question of whether suicidologists, of any and all stripes, should be expected to have a core knowledge and/or competency, especially if presenting oneself to the public as an expert in the subject matter of suicidology.

\section{On Defining Suicidology's Core Knowledge and Practice Competencies}

The Phoenix conference underlined the need for increased attention to education and training in the field and recommended the development (and federal funding) of four levels of training programs, including: (a) researchers, both clinical and "pure," (b) treatment specialists, (c) education and training specialists, and (d) administrators and service deliverers. At the time, the NIMH supported two Fellowship Training Programs in Suicidology, one at the Johns Hopkins University School of Medicine and the other at St. Elizabeth's Hospital in Washington, DC. Soon after the Phoenix conference report was released, the US federal government stopped funding professional training programs such as these (until then, training was known as the fourth leg of what now became a three-legged stool of government funding - the three other legs are research, services, and treatment), and the recommendations from the conference went unheeded forevermore.

Over the years, a great deal has been written about the need for training, notably in the assessment and management of suicidal patients (compare Schmitz et al., 2012). A large number of gatekeeper training programs have been implemented and specific training programs abound for anyone interested, in addition to more advanced training in specific modalities such as the psychological autopsy. In a sense, suicidology is a field without boundaries. The pathways to becoming a suicidologist are diverse and one's qualifications to claim even a modicum of expertise in the subject matter of suicidology remain ill-defined, if at all. No less, claiming to be a suicidologist is not synonymous with defining oneself as an expert (Bourne et al., 2014) and some argue that one can be an "expert by experience," a designation reasonably applied to both loss survivors and individuals with lived experience whose personal life stories can well inform the delivery of mental health and social care services (https://www.cqc.org.uk/about-us/jobs/ experts-experience).

\section{On Professional Competence}

Most professional codes of ethics have a specific and enforceable standard addressing how to establish, maintain, and expand competence. Competence involves having an essential base of knowledge, technical skills, and attitudes in addition to having a set of values and reasoning skills to implement services for the benefit of the individual and/ or community (Barnett, 2017). Mental health professional board certifications typically focus on clinical competence and evidence of such clinical competence underlies the granting of licensure by the state.

Clinical caregivers and researchers ("specialists") are expected to abide by the codes of ethics of their professional associations that specify competence as one of their governing principles. As examples, the American Psychological Association's code of ethics states that: "Psychologists provide services, teach, and conduct research with populations and in areas only within the boundaries of their competence, based on their education, training, supervised experience, consultation, study, or professional experience" (https://www.apa.org/ethics/code). Similarly, The UK Royal College of Psychiatrists' code of ethics specifies that psychiatrists have an "ethical duty to maintain competence and knowledge" (www.rcpsych.ac.uk > collegereports > college-report-cr186).

In this regard, we believe that suicidology has sufficiently matured to be able to define both its core knowledge and that knowledge that would be specific to its various subspecialties (research, public policy, clinical care, postvention services, etc.). The field's core knowledge might include, at a minimum, a basic understanding of (a) the epidemiology of suicide and of how to access current epidemiologic data, (b) research-based risk and protective factors, (c) principles of risk assessment and treatment, and (d) evidence-based strategies for prevention, intervention, and postvention. Specialists should be expected to understand and display expertise in subspecialty specifics such as methodology (researchers and clinicians), suicide-specific forms of psychotherapy (clinicians), logic modeling (prevention specialists), and complicated grief (postvention specialists). We are not, herein, outlining in any detail just what might comprise core and specialty-specific knowledge topics, but do assert that the field and its research base has matured sufficiently for this to be done. Notwithstanding the eventual development of free-standing training programs in suicidology, the establishment of the field's core knowledge would inform contemporary training programs and university-based curricula in suicidology, so far poorly implemented or totally absent (Hawgood et al., 2008). The only currently existing academic degree program, a Master in Suicidology, is at Griffith University in Australia. It emphasizes the importance of research-based studies with an 
intent "to produce graduates who are knowledgeable and skilled in the identification of a range of concerns regarding suicidal behaviours and their planned management ... (including research, public policy, and ... prevention)" (https://www.griffith.edu.au/study/degrees/master-ofsuicidology-5666)

\section{Is There a Need for Certification and Titling of Clinicians Working With Suicidal Patients?}

Were suicidology to establish the extent and limits of its core and specialty knowledge bases, questions arise as to whether the field should test for an acceptable level of mastery of that knowledge, leading to a process of certification and credentialing of those working with suicidal patients who demonstrate that mastery, no less what governing/examining body should administer such a certification program. Embedded in these questions is whether or not a certification program that attests to an individual's mastery of a defined subject matter is sufficient to allow that individual to claim and use the title of suicidologist.

In many countries, the use of the title "psychologist" is protected by national laws, typically requiring a minimum level of graduate training and licensure (https:// en.wikipedia.org/wiki/Psychologist). In the United States, the title of social worker is protected by state laws, but currently only so in 36 states (http://naswct.org/advocacy/title-protection/states-with-title-protection/). In the United States, there are no legal restrictions surrounding the title of psychotherapist, while in the United Kingdom, the title of psychotherapist is partly protected by the country's Council for Psychotherapy (https://www.psychotherapy.org.uk/registers-standards/about-our-register/), but not by statutory regulation (https://www.bacp.co.uk/ news/news-from-bacp/2020/6-march-government-update-on-statutory-regulation-of-counsellors-and-psychotherapists/). The practice of psychotherapy in Italy is limited to psychologists and to medical doctors (if they have a specialization in psychotherapy), to psychiatrists, and to child neuropsychiatrists (https://cdn.ymaws.com/www. psychotherapyresearch.org/resource/resmgr/imported/ events/barcelona/reports/report_italy.pdf). In Australia, the titles of chiropractor, nurse, and optometrist are all protected by national law (https://www.ahpra.gov.au/ News/2014-01-24-media-release.aspx). We know of no country that legally titles the term suicidologist.

A process of certification would assure the public that individuals claiming to be suicidologists have met certain standards of education, training, and knowledge- competency. In countries where legal issues associated with suicide are brought to court and experts are called to testify, such a process may serve to assure the court that the expert is properly qualified.

Concurrently, developing and administering such a process would be cumbersome, expensive, and political. Were such a system to be created and implemented, it is unclear whether individuals currently claiming the title of suicidologist would bother getting certified in the absence of any legislative mandate to do so. Likely, there would be need for a "grandfathering" period (and associated criteria) for those with established expertise to be certified without requiring further education or examination. Furthermore, a certification system would require consideration of the need for recertification after a specified number of years to ensure that one's knowledge is sufficiently current; in addition to questions as to how to ascertain whether a candidate suicidologist could apply that knowledge in specialtyspecific ways, that is, displayed practice competencies or expertise. Further, as yet, there are no national or international organizations entrusted or authorized to investigate qualifications, and/or examine the content knowledge of individuals claiming to be suicidologists.

\section{Would Certification and Titling Advance Suicide Prevention?}

Clearly, this could be the congruent outcome of such a formalization process of professional preparation and training. In addition, if we really think, "Suicide Is Everyone's Business" (and we certainly think it), pushing in the direction of an approach to suicide prevention through the idea of a core knowledge of the subject (comprising the main elements described above, such as epidemiology, risk factors and protection, risk assessment, etc.), this could only be an improvement. If the training process manages to free itself from the medicalization of stress to instill a truly multidisciplinary perspective, capable of taking into account transcultural differences and demonstrating attitude and sensitivity to the sociopolitical context and to the influences of its changes, then such type of shared core knowledge could really translate into a concrete advancement of suicide prevention. As White and associates argue in their volume Critical Suicidology (2016), it seems that suicidology has become too focused on the biomedical paradigm, which is a model that considers distressed conditions as a pathology and does not emphasize enough the social, political, and historical contexts that can have an important role in causing human suffering (see also Silverman \& Berman, 2020).

"It never fails anyone a good reason to kill himself," Cesare Pavese said in Mestiere di Vivere (The Job of Living, 
1938). This means that the suicidal option can become present in the life of each of us, should the living conditions become too difficult to bear. The transition from a conception of suicide prevention based solely on individual mental health to the broader attention and interpretation of socioenvironmental contexts (Marsh, 2020) is unavoidable for an effective prevention strategy. In this direction, all disciplines involved in the "Job of Living" should integrate and promote a global reading of the individual, still capable of discerning the various components that contribute to suicidal ideation, while maintaining the holistic approach.

If this vision were at the basis of promoting progress toward more effective suicide prevention, then the universalization of core knowledge could probably justify certification and titling.

\section{Conclusion}

With "Suicide Is Everyone's Business" we heartily embrace the need for and value of gaining input from all sectors to inform and promote our aspirations to prevent suicide. By bringing together diverse voices and backgrounds and a global perspective, we suggest that a timeline, process, and consensus model could be used to advance what was stated 50 years ago and is now on the cusp of becoming a reality. A half century after the Phoenix conference, it is perhaps time to heed the call for suicidology to define its core knowledge and promote specific university and training curricula, if not criteria for the eventual certification of individuals who want to claim for themselves the title of suicidologist.

In this editorial, our goal has been to raise issues and concerns pertaining to the enhancement of suicidology and the identification of suicidologists. We recognize that some of these issues may be challenging and difficult to resolve. Our intent is to not exclude anyone from the big tent of suicidology, but, rather, to advance the maturation of our field and the better accomplishment of its aspirational goals.

\section{References}

Barnett, J. E. (2017). Understanding competence. The Specialist, 37(1), 15-18.

Bourne, L. E., Jr., Kole, J. A., \& Healy, A. F. (2014). Expertise: defined, described, explained. Frontiers in Psychology, 5, 186. https://doi. org/10.3389/fpsyg.2014.00186

Goldney, R. D., Schioldann, J. A., \& Dunn, K. I. (2008). Suicide research before Durkheim. Health History, 10(2), 73-93.
Goldney, R. D., \& Schioldann, J. A. (2000). Pre-Durkheim suicidology. Crisis, 21(4), 181-186. https://doi.org/10.1027//02275910.21 .4 .181

Hathorne, B. C., \& Resnik, H. L. P. (1973). Suicide prevention in the 70s. US Government Printing Office.

Hawgood, J. L., Krysinska, K., Ide, N., \& De Leo, D. (2008). Is suicide prevention properly taught in medical schools? Medical Teacher, 30, 287-295. https://doi.org/10.1080/01421590701753542

Marsh, I. (2020). The social production of psychocentric knowledge in suicidology. Social Epistemology, 34(6), 544-554. https://doi. org/10.1080/02691728.2020.1725920

McCormick, A. (2010). Infant mortality and child-naming: A Genealogical Exploration of American Trends. The Journal of Public and Professional Sociology, 3(1), Article 2.

Pavese, C. (1938). Il Mestiere di Vivere [The job of living]. Einaudi.

Schmitz, W. M., Jr., Allen, M. H., Feldman, B. N., Gutin, N. J., Jahn, D. R., Kleespies, P. M., Quinnett, P., \& Simpson, S. (2012). Preventing suicide through improved training in suicide risk assessment and care: an American Association of Suicidology Task Force report addressing serious gaps in U.S. mental health training. Suicide \& Life-Threatening Behavior, 42(3), 292-304. https://doi. org/10.1111/j.1943-278X.2012.00090.x

Shneidman, E.S. (1989). A life in death. In C. E. Walker (Ed.), The history of clinical psychology in autobiography (p. 255). Brooks/Cole.

Shneidman, E. S., \& Swenson, D. D. (1967). Bulletin of suicidology. U.S. Government Printing Office.

Silverman, M. M., \& Berman, A. L. (2020). Feeling ill at ease with a new disease. Crisis, 41(4), 241-247. https://doi.org/ 10.1027/0227-5910/a000726

Weisz, G. (2003). The emergence of medical specialization in the nineteenth century. Bulletin of the History of Medicine, 77(3), 536-574. https://doi.org/10.1353/bhm.2003.0150

White, J., Marsh, I., Kral, M. J., \& Morris, J. (2016). Critical suicidology: Transforming suicide research and prevention for the $21 \mathrm{st}$ century. UBC Press.

Published online March 12, 2021

\section{Alan L. Berman}

Department of Psychiatry and Behavioral Sciences

Johns Hopkins University

School of Medicine

Baltimore, MD

USA

drlannyberman@gmail.com

Alan L. Berman, PhD, is Adjunct Professor of Psychiatry, Department of Psychiatry and Behavioral Sciences, Johns Hopkins School of Medicine, USA. He is Past-President of the International Association for Suicide Prevention (2009-2013) and served as Executive Director of the American Association of Suicidology between 1995 and 2014

Morton M. Silverman, MD, is Assistant Adjunct Professor of Psychiatry, Medical College of Wisconsin, Milwaukee, WI, USA, and Distinguished Life Fellow of the American Psychiatric Association. From 2004 to 2017 he served as Senior Science Advisor to the Suicide Prevention Resource Center. He was Editor-in-Chief of Suicide and Life-Threatening Behavior between 1996 and 2009.

Diego De Leo, PhD, is Emeritus Professor of Psychiatry, Doctor of Science in Psychogeriatrics and Suicidology, and Emeritus Director of the Collaborative Center of the World Health Organization (WHO) for Research and Training on Suicide Prevention of the Australian Institute for Research and Suicide Prevention at Griffith University in Brisbane, Australia. 
Daniel Reidenberg, PsyD, is Executive Director of Suicide Awareness Voices of Education, Managing Director of the National Council for Suicide Prevention, and Special Advisor to IASP. He is co-chair of the International Media and Suicide Task Force, a certified psychological autopsy investigator, and on several editorial boards. 